\title{
MAPPING EVENKI LAND: THE STUDY OF MOBILITY PATTERNS IN EASTERN SIBERIA
}

\author{
Tatiana Safonova, István Sántha
}

\begin{abstract}
In this article the Evenki way of moving is studied with an intention to reformulate the place of movement in modern hunter-gathering cultures. Firstly, the data collected during the fieldworks among two Evenki groups will be presented in a form of special maps carrying information not only about the routes but also various activities. Both groups are cut from each other by a mountain ridge and live in slightly different ecological and social environments, which have a contribution to the difference in their movements. With the one group of horse herders living on the frontier between steppe and taiga and the other group relying on reindeer herding and living deep in taiga, the consequential differences in their mobility routes did not touch the basic patterns in the way their mobility is organized. The second part of the article is devoted to one of this shared basic pattern, the way the Evenki walk by foot. This part is devoted to a comparison between how this cultural practice is understood by Buryats, cattle breeding people, and our own interpretations based on fieldwork materials. The comparing of this two views of outsiders on the one of the most basic and routine practice will give the opportunity to study the relationship between a specific way of moving and hunting. The remained part of the article tracks the interrelations between such aspects of Evenki culture as ways of moving, the idea of self and territory organization.
\end{abstract}

Key words: Evenki, landscape, maps, walking

Hunter-gatherer communities are usually very mobile, the trips they conduct in a year could cover thousands of kilometers ${ }^{1}$. Modern hunter-gatherers even when sedentary manage to spend most of their time travelling, practicing hunting and foraging in the vast surroundings of their villages and camps. Evenki hunters of East Siberia present a fine example of such a mobile ethos. During our fieldworks amongst two neighbouring Evenki groups we discovered that the everyday routines at camps and villages consist of packing and preparations for various trips, in the direction of the central settlements or to the taiga, waiting for somebody and welcoming the returning people. Sometimes these trips took most of the family resources, increased petrol usage and were time consuming, bringing no obvious benefit to the families fortunes. Yet still the emotional reward of moving seemed to outweigh any material losses. 
In this article we will try to delve into Evenki movements and formulate its place in modern hunter-gathering culture. In the first part of the article with the help of special maps we will show the data we collected during our fieldworks on various routes that the Evenki take through their territories. Here we will compare two families from neighbouring Evenki groups that are cut off from each other by a mountain ridge. These families live in slightly differing ecological and social environments. One family is more involved in cattle and horse breeding and lives on the frontier between steppe and taiga. The other relies on reindeer herding and lives deep in the taiga. Despite the obvious differences in their mobility routes we have discovered that there are basic common patterns in the way their mobility is organized. The second part of the article is devoted to one shared basic pattern, the way the Evenki walk on foot. In this part we compare this cultural practice with the information we get from the Buryats, cattle breeding peoples, on the way they walk. The presented differences will help return to the problem of relations between specific ways of moving and hunting. In the last part of the article we will track the interrelations between various aspects of Evenki culture such as ways of moving, the idea of self and territory organization.

\section{METHODOLOGY}

The strategy for the study of mobility of hunter-gatherers depends on the analytical frame through which the notion of hunter-gatherers is interpreted. The classical approach is to see them as people that practice a special kind of huntergathering subsistence, and as a result their mobility is an inevitable part of it. For example, Kelly (1995) summaries the basic approaches to the mobility of hunter-gatherers looking at the residential and logistical forms of it. He assumes that the most common goal, besides changing places, is maintaining information about the current and potential state of resources. A traditional subsistence approach focuses on the natural environment and natural resources that are used by hunter-gatherers, such as springs, wild animals and plants. But Kelly also makes slight hints on the changes in these environments of modern hunter-gatherers and speaks about the shifting of the mobility modes to a form of associated foraging, when the routes taken by people depend on the centers and settlements where un-natural resources are accumulated such as petrol, alcohol, bureaucratic and education institutions.

The other strategy is to study moving not as a part of subsistence strategy, but as a form of cultural existence. Here it is possible to do so either through the study of narratives devoted to moving (Kwon 1998, Legat 2008) or the 
embodied skills of walking (Tuck-Po 2008, Widlok 2008) in the tradition of "communities of practice studies" (Lave \& Wenger 1991). Both approaches help to illuminate tacit processes of culture transmission and socialization.

In the frame of this research we tried to combine the strengths of both approaches and study the patterns of Evenki mobility that are embedded both in the local social and natural ecological system and the cultural system presented by the Evenki hunter-gatherer ethos. The analytical vocabulary that seemed most suitable for this purpose we took from Gregory Bateson, that developed the cybernetic approach equally effective for the study of social and natural phenomenon (Bateson 1972). The research question that we were engaged with in the frame of this study could be formulated as the following: How does the spatial mobility of modern hunter-gatherers in Siberia reflect the internal cultural processes and ethos transformations aroused by rapid changes in the outer social and natural environments. We came to the conclusion that the way the Evenki move in itself is one of the mechanisms of cultural preservation or adaptation. Routes can be changing, forms of transport can also be different, but the basic patterns of the movement organization stay the same. They are so deeply connected with internal elements of the Evenki self that as a result they facilitate the strengthening of the Evenki ethos and changes in the outer world do not lead to dramatic changes in the constitution of Evenki culture. In summary, the following parts of the article show different aspects of this self-correcting mechanism of culture adaptation (Bateson 1980).

The Evenki (35 000) are one of the few hunter-gatherer peoples living in Russia. They speak a northern Manchu-Tungus language. They live in small groups, 200-300 people scattered between the Yenisei River and the Pacific Ocean. They entered social history because the word "shaman", now used worldwide, comes from their language. Their social organization prefers egalitarian relationships. They have elaborated a complex strategy to communicate and interact with the Russians and other surrounding societies (Russians and other Slavic peoples, furthermore Buryats and Chinese) ruled by authoritative relationships. Recently two processes could be observed among Siberian huntergatherers. On one hand their communities become more and more isolated, on the other hand newcomers (mostly Russians) massively migrate to their areas in search of economic profits from taiga-forest exploitation. However anthropologists have witnessed that the Evenki culture is not devastated even where the Evenki language is being lost. Evenki people maintain their customs and behavioral patterns such as routine sacrifices to the spirit of fire and successfully include new technologies into their everyday life (petrol saw, tractor, etc.). 
The following study is based on the field works, totaling two years between 1995 and 2009 among different Evenki communities living in the Baikal region. In this study we compared two neighbouring regions in East Buryatia, Baunt and Kurumkan, where Evenki people live. The authors worked as anthropologists for 16 months in these regions: in Baunt two months in 2004, and ten months in 2008-2009 and in Kurumkan 4 months in 2006. Baunt Evenki are Orochens, 'reindeer herders', Kurumkan Evenki are Murchens, 'horse keepers'. Reindeers and horses are used for transportation during their main activity of hunting. ${ }^{2}$

\section{MAPPING EVENKI ROUTES}

Evenki wander between situations or events that provoke and intensify the circuits of companionship (Safonova \& Sántha 2007) and experiences of autonomy (Ssorin-Chaikov 2003), rather than geographical points. With this in mind, describing Evenki land with an ordinary map imposed with spots and symbols on the continuous space or landscape becomes a real challenge. But if we inverse the main premise of map making in accordance with the logic of Evenki social organization we construct a depiction of Evenki land which will also grasp important traits of the Evenki mind. The task is easier than it seems, because the streams of Evenki paths covering their land are analogous to the changes (experiences of autonomy) from one companionship to another. Mapping Evenki land with an Evenki social organization could help us to find other such analogies between places and social interactions.

The presented article includes 10 maps (5 pairs), which are not cognitive maps. We drew them to summarize the results of the project. We traveled and walked together with Evenki people in their environment and observed and practiced the skills which are necessary for living in this environment. These maps are not ordinary topographic maps. Only, the first pair of maps, as the starting point in our 'map project', contains names and landmarks, similar to the ordinary topographic maps. In ordinary life people associate places more with the actions they do there, than with official names. At the same time, when we started drawing these maps it turned out that the whole process of map making is based on a hierarchical pattern with some information subordinated to other information. For example, the network of rivers is subordinated to the roads, and blue lines are covered with black ones. To maintain the Evenki way of perceiving the environment, we had to change the colors and break associations with the standard hierarchical organization of information, and make various maps in which different information is depicted in different 
constellations - presenting the situated character of the landscape order. That proved a rather difficult task, and it will be hard for the reader to learn to use these visual materials we called horizontal maps.

We constructed maps of two neighbouring places in which Evenki live. These places are separated by a high ridge, which presently people do not cross, preferring instead to travel through the central city by bus. Evenki living in these two, separate places do not have a strong relationship with each other, although they may be distant relatives.

Two main differences predetermine the infrastructure of these places; the scale of the inhabited territory, and the landscape. The groups are roughly the same size and share much in common while living in very different environments. Knowing how these common traits evolved and why this happened will help us determine the premises of the Evenki mind constituting the same patterns, modified in accordance with the environment. In constructing these maps, we focused on the activities and life circumstances of two Evenki families living in the taiga, neither too far from the village nor from the reach of strangers.

The family of Grandfather Orochon lives in the first region (Kurumkan). It is covered with patches of steppe surrounded by taiga and crossed by numerous big and small mountain rivers, which flush their waters into the Barguzin river. Here Evenki live 15 or fewer kilometers from the village, the only gate into civilization, though the village itself is a rather undeveloped and gloomy place. Here Evenki breed cattle, horses and cows.

In the Baunt region, the family of reindeer herder Maradona (this nickname comes from his real family name - Mordonov) lives more than 100 kilometers from the village, but his summer camp is near the pathway along which all-terrain vehicles are circulating between the district center and the nephrite deposits. This area is covered with mountain taiga, strong rivers, and unstable roads.

The first two maps depicting the main roads, pathways, rivers, and summer and winter habitations, show the strange context and environment in which the Evenki live. A comparison of the two areas shows how the scale of the inhabited territory strongly effects how these objects interrelate with each other.

If travelling longer distances, people must be more independent and autonomous from any strange or general contexts, because they may deal with serious risks. Beginning a trip that will take several days without any communication with others is a situation in which you cannot afford to make a mistake, or have an accident which you cannot resolve without help. To minimize risks you must concentrate on travelling and avoid complex intrusions of other 
contexts. This is why roads and rivers are interconnected and coordinated in Baunt, more than Kurumkan, and why lines of transport trajectories are much straighter.

Another type of infrastructure development, which can be associated with soviet era territory management, can be found in Kurumkan (see Map 1.1). In Kurumkan it was typical to build a network of roads not necessarily orientated to preexisting communication. New roads have been built not for people, but for cars, with price and ease of building taken into greater consideration than efficacy of logistics. As a result, the main Baikal-Amur Magistral (BAM, the alternative to the Trans-Siberian Railroad) railroad built in the Kurumkan region to bring railroad supplies to the neighbouring district is presently not very useful for local transport. Numerous small roads built to help construct the BAM remain, but do not connect important places. To get from one place to another people have to combine and make loops through existing roads. The structure of roads does not take into account the numerous rivers, making travelling in the region even more difficult. As a result, people are dependent on the roads which were built for projects that do not exist any more. This makes travelling more complicated by the strong possibility of accidents.

In Baunt, people try to determine their routes without integrating predetermined landmarks and landscapes. They do not use the few roads in this region to plot their routes through the taiga, but use the roads without a predetermined path. The infrastructure depicted on Map 1.2 shows a system of roads and rivers connected to provide channels between the main destinations: villages, summer camps and deposits. This network of channels is constructed within the non-Evenki framework of nephrite excavation, but resembles the way Evenki used to travel. Groups of people travelling across these channels are autonomous teams who can deal with potential risks without external help.

The other important difference that exists between regions is the position of Evenki people and their attitude towards contact with strangers. In Kurumkan, because of the proximity of the village and the existence of numerous roads, the Evenki are not cut off from the outside world and may even be intent on restricting contacts. The Evenki may even exaggerate the complexity of travelling here to prevent the intrusion of strangers. In the Baunt region, however the Evenki live far from the village, and cannot go there whenever they want, but are interested in strangers travelling to them. 
Mapping Evenki Land:The Study of Mobility Patterns in Eastern Siberia
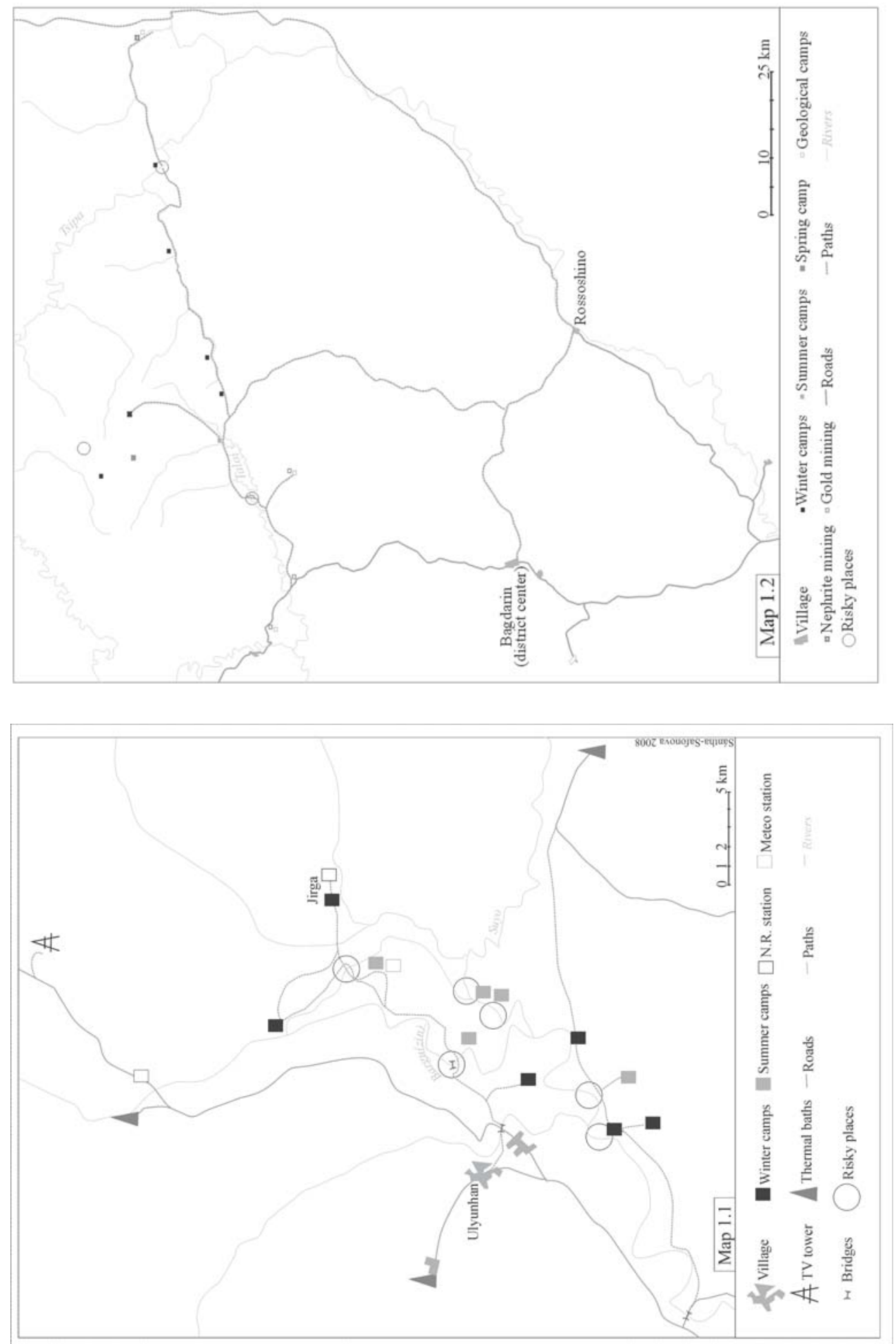


\section{PATHWAYS AND ROADS}

The next set of maps show the various means of transport used in these areas. These maps show seasonal changes in logistics. It is difficult to guess whether people live in places because they are reachable, or if places are accessible because people live there. With the Evenki, however, it is clear they live in open (which can be reached by strangers) places in one season, but stay far from outside communication in another. Though these rhythms of communication and avoidance are common in both regions, the yearly cycles of movements in Kurumkan and Baunt are the inverse of each other.

Map 2.1 shows destinations that can be reached by car and by foot in Kurumkan. Most places on the map are accessible by foot, but not all can be accessed by car. Places beyond the map can only be reached by car, and are dominated by strangers (Buryats or Russians who can afford cars and petrol). This divides the territory into zones controlled only by Evenki (only Evenki will try to reach these places by foot) and zones of potential contact between Evenki and strangers.

In winter, Grandfather Orochon's family stays at the winter camp, which is connected to the village by road. This road is usually unproblematic for drivers in winter due to the firm ice on the rivers crossing it. During this time, the Evenki go to the village at least once a week. In summer they migrate to the summer camp, separated from the mainland by the Sujo river, which they cross only by boat. In summer, their travels are reduced to short trips between the summer and winter camps. Stepan's family stays at the summer camp and carries out the tasks involved with cattle breeding. Elder people stay at the winter camp, which becomes a kind of summer camp for the children of relatives living in the village. As a result, winter becomes a season of intense contact and heavy drinking in contrast to the summer, which is associated with isolation and hard work.

Map 2.2 shows the relative distance from the Maradona family to settlements and villages. In summer, they live approximately in the middle of the main route between the district center and the nephrite deposit, which means they host teams (official brigades as well as poachers) travelling between the deposit and the village at least once a week. These brigades carry food and other supplies the Evenki ask for in advance, especially vodka. When in Kurumkan, Evenki themselves go to the village in winter, in Baunt, they receive guests in summer with the same frequency, approximately once a week. This open season, when they search for contact with strangers, is not predetermined by the household cycle of tasks, because reindeer need places of much 
Mapping Evenki Land:The Study of Mobility Patterns in Eastern Siberia
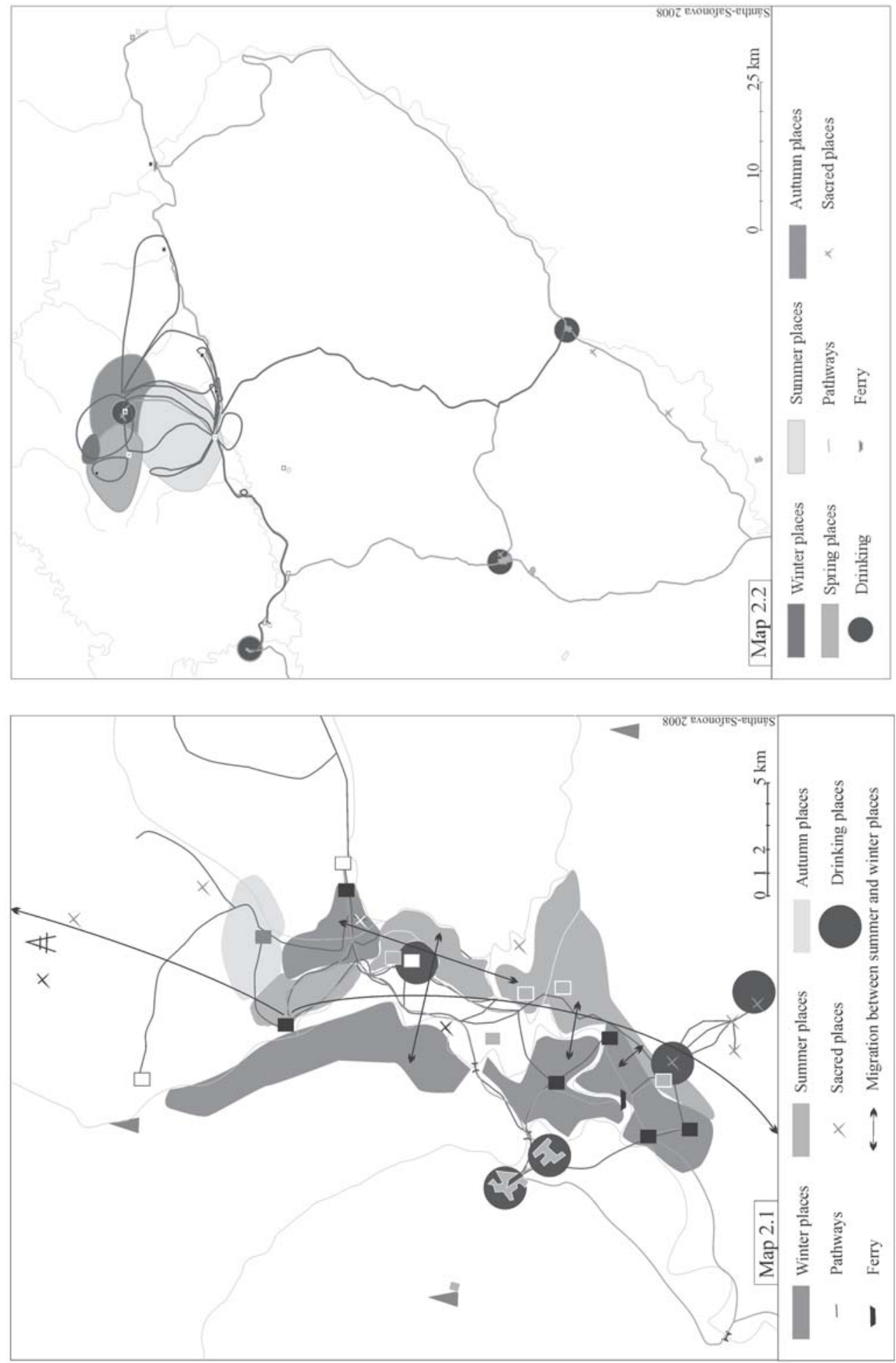
higher in altitude in summer because of the heat and insects. Evenki do not plan based on the needs of their reindeer, but on the calendar of strangers. In winter, they migrate to the winter camp, which could also be reached by car, but is ten kilometers from the road to the deposit. During this time, when there is no nephrite extraction, visitors are rare.

As we can see, in both cases, the season of communication for the Evenki is predetermined by strangers or strange obstacles, such as the timetable of workers or the state of roads. But in both regions these seasons last approximately seven months, from October until April in Kurumkan, and from April until October in Baunt. In accordance with their interaction with strangers, the Evenki can manipulate this schedule. For example, they can migrate to the summer camp later in Kurumkan to prolong the season of leisure. Or, they can migrate to the winter camp in Baunt earlier if tired from intensive interaction and frequent visits by strangers. Evenki use household needs as a scapegoat for these manipulations, but the Evenki can easily reverse their decisions and return to the camp or unexpectedly leave it. The motivation behind these changes is the wish to balance periods of solitude with periods of intense communication. These observations lead us to the conclusion that for the Evenki, household duties serve as an instrument in managing communication; their lifestyle and calendar of migration is not predetermined by the household economy or traditions (whether connected with cattle breeding or reindeer herding), but are based on their communicative strategy. Success of the household is not based on the number of reindeer or amount of stock, but its flexibility and ability to keep the fragile balance between involvement in and avoidance of communication with the outer world.

Maps 3.1 and 3.2 show the zones in which Evenki participate in companionship and pokazukha (the pattern of behavior based on the expectations of strangers and not on Evenki intentions). Zones of companionship differ in shape and are much less bound to objects of infrastructure, they cover a great deal of space in both regions. Here, Evenki hunt, fish, travel and execute other tasks, regaining collaborative coordination of mutual actions without sophisticated narratives. Places covered with geometric circles are object-bound situations, during which the Evenki cannot avoid contact with strangers and behave according to their stereotypes or expectations. Places dominated by pokazukha interaction, without the possibility to establish companionship, are sacred places appreciated by local Buryats; cordons and houses left after the kolkhos, TV towers and resorts with spring water. Strangers can usually access these places, and because of this, the Evenki cannot establish their own, private interests. In Kurumkan, pokazukha and companionship coexist only in the main villages. These spaces provide the buffer zones between the stranger and Evenki places, 
Mapping Evenki Land:The Study of Mobility Patterns in Eastern Siberia
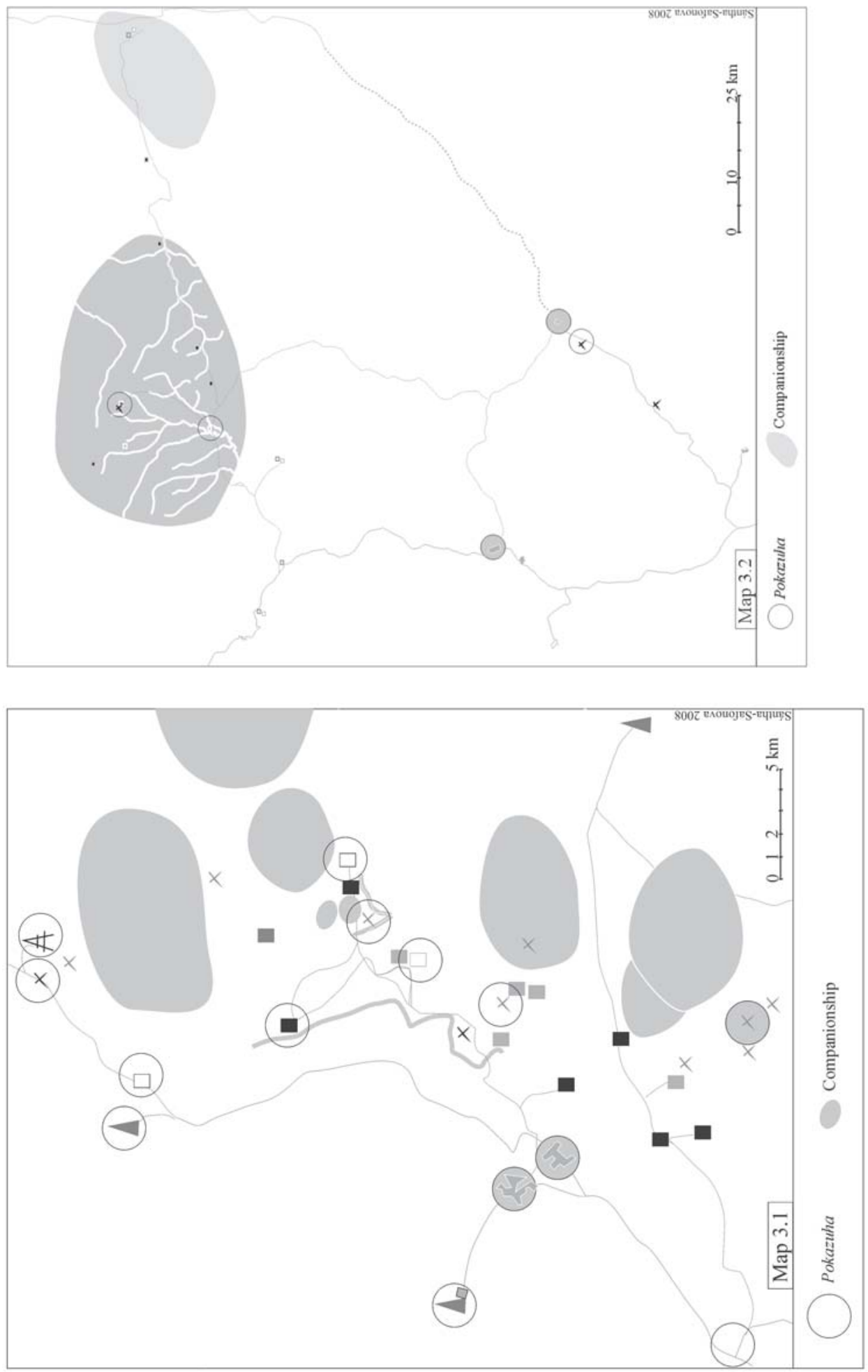
and most exchanges take place here. In Baunt, pokazukha exists exclusively in one place. In all other places, pokazukha is always counterpoised with the possibility to establish companionship. Pokazukha, like a point on the map, has no continuity and no relationship with the context of the outside world. The frontiers of the zone of companionship are not strictly justified, and are deeply connected with the context (landscape, routes and seasons).

\section{CHILDREN AND DOGS}

Maps 4.1 and 4.2 show the movements of Evenki children of different ages. Children stay with their mother or relatives in the village until the age of two or three. When the child can walk, he/she joins the parents at the winter camp in Kurumkan, and at the summer camp in Baunt. During the season of isolation he/she returns to the village. Between the ages of three and seven, the child stays with his/her parents in the taiga and migrates with them to the summer and winter camps. After the age of seven, when the child enters boarding school, his/her independent life begins. After that he/she stays independently at the boarding school, and joins his/her parents in summer, but can easily leave them to visit friends or carry on their own business. Evenki children from the village follow similar patterns, they stay with their parents until the age of seven when they enter school and migrate to the winter camps to live with their elderly relatives during summer vacation. They follow trajectories much closer to town children, who spend their summer vacations with their grandparents in the village (although they travel from the village to the winter camp, situated in the taiga). These personal circles of movements change due to much wider circles of movements made by Evenki families. All of the Evenki families we met lived for periods (from one to ten or more years) in the town, village and in the taiga (in summer and winter camps).

This constant movement from early childhood provides a crucial element in the nomadic socialization. For Evenki children living in the taiga, three distinct periods appear in their life, which can be linked with the Piagetian psychology of development stages. The first stage occurs in the village before the child can walk and participate with adults in the first and most important companionship by walking together. As soon as a child can walk with adults, he/she starts to live with his/her parents in the taiga. During this phase, he/ she is cut off from the village and spends his/her time at summer or winter camps learning to participate in a wide range of companionships. The child becomes an integrative part of the conjugal unit. At the age of seven, with the first experience of pokazukha behavior, learned during the first days at school, 
Mapping Evenki Land:The Study of Mobility Patterns in Eastern Siberia
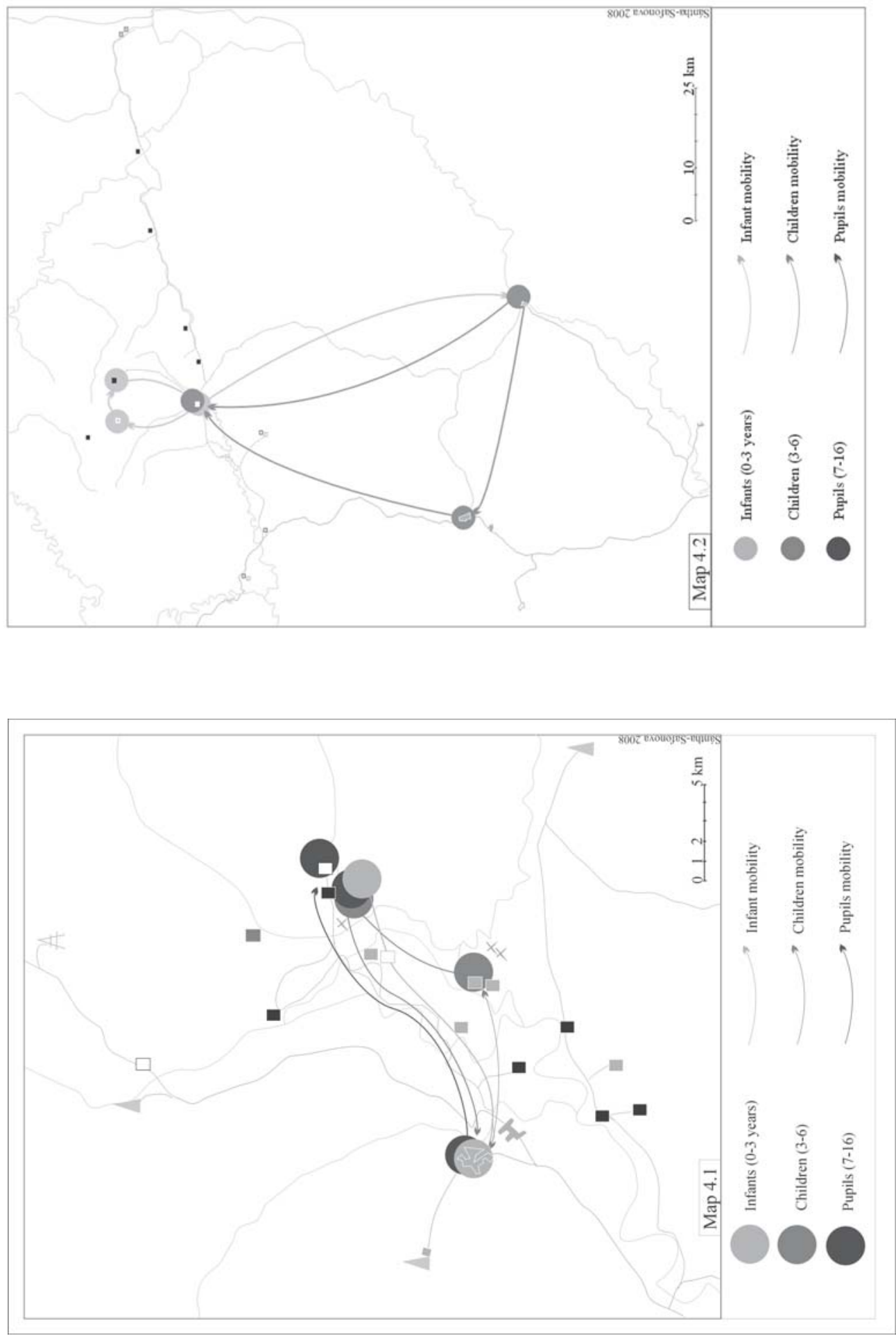
the child becomes relatively autonomous from the parents, sharing fewer and fewer companionships with them by establishing his or her own companionships with other people.

The autonomy that evolves from the age of seven comes from the ability to walk and travel alone. This experience of manakan ('making your own way' in the Evenki language) is crucial for the development of Evenki ethos. The territory also plays an integral part of this ethos, because the areas one can walk through alone predetermine the tension of manakan feeling. Evenki land in the Kurumkan district is rather small, and distances can be covered much easier, but the experience is less impressive than in Baunt, where travel from the summer camp to the village consists of several days of risky solitude. The Evenki ethos also applies to the characters of Evenki dogs, which share a great deal with their human companions.

Maps 5.1 and 5.2 show the routes and places where we find more Evenki dogs living. In Kurumkan, the routes of Evenki dogs are identical to the routes of Evenki children age seven and older. Here, dogs freely travel from the village to the winter camp as the trip is neither difficult nor dangerous. Although some dogs prefer not to go to the village and wait for their human companions in the taiga, they still show traits of autonomy. In Baunt, Evenki dogs are much more like Evenki children of between three and seven years old, and try to stay with their human companions at all times. This could be explained by the great distance between the village and the camp, which is impossible for the dog to cover alone.

These observations highlight the difference between how Evenki from Kurumkan and Evenki from Baunt experience their initially common ethos. For the Kurumkan Evenki, they become autonomous through the land much earlier than their Baunt neighbours, but their experiences are less impressive. Their autonomy does not give them satisfaction, and they compensate the absence of danger and risk by drinking. In the Baunt region, Evenki who remain in the village the whole year are in the same position as the Kurumkan Evenki. Those who live in the taiga, however, struggle for their autonomy and experience it in more difficult circumstances, making them less dependent on alcohol, though they also can be deeply affected by it.

Comparing Baunt and Kurumkan, we see the self-corrective systems (Safonova \& Sántha 2007) that evolve in these regions are wonderfully counterbalanced. Children's movements balance the movements of their parents. The autonomy of dogs is counterbalanced by the addictions of people. Spots of pokazukha exist with zones of companionship. The intensity of contact or solitude follows similar seasonal timeframes in both regions. The difference in dis- 
Mapping Evenki Land:The Study of Mobility Patterns in Eastern Siberia
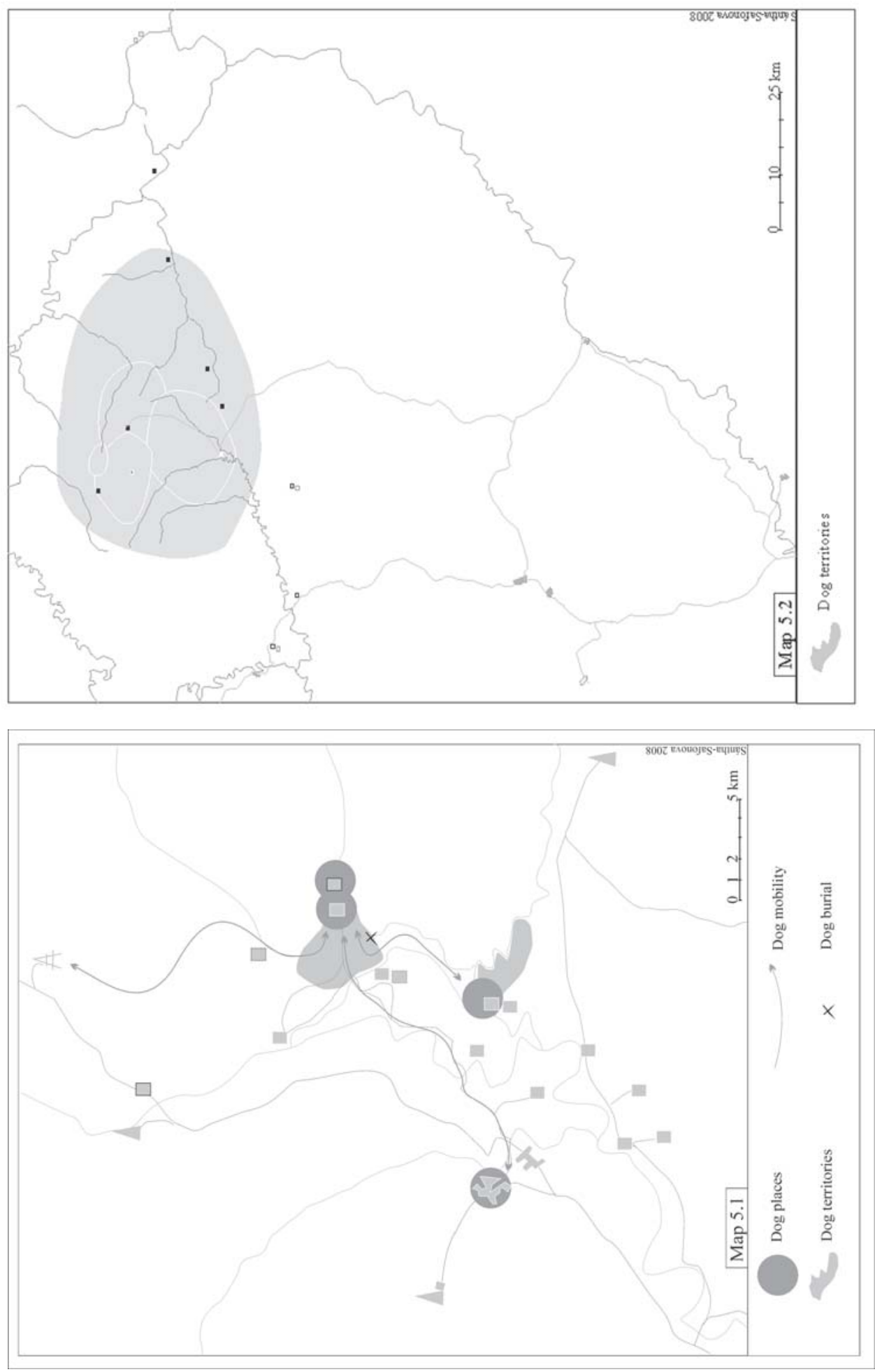
tances affects the ratio of interaction with strangers and isolation. The patterns that evolve are the same, though stretched due to the distances that these patterns cover.

\section{WALKING AS CULTURAL PRACTICE ${ }^{3}$}

Walking is a relatively new and increasingly popular topic at the moment, and we may in this context recall the book "Ways of Walking. Ethnography and Practice on Foot", edited by researchers from Aberdeen University (Ingold \& Vergunst 2008). The following arguments presented here are the results of collaborative fieldwork that the authors conducted in 2006 among the Evenki people in the Baikal region. In the course of the study it turned out that we could not continue our studies avoiding the topic of walking. Walking together proved to be a format for interaction and communication between local Evenki and strangers (including anthropologists).

Walking is an activity that reveals several levels of cultural diversity, as the technique of walking, routes and rhythms of movements can be traits that are not shared by different cultures. What this means is that the mutual accomplishment of walking is a situation of cultural contact; people who walk together are communicating with each other and coordinating mutual actions and decisions. In doing so, they need to overcome differences in socialization. For example, for Bargai (Ekhirit-Buryat shaman; Safonova \& Sántha 2010a), the Evenki way of walking was a mystery, because for Buryats the ability to walk is less important than the ability to stand. An Evenki child is accepted as an individual when he or she is able to walk alone, whereas for the Buryats a child becomes a human when he or she is able to stand upright. This difference in the starting point of the socialization process crucially affects the way people walk. The Buryats prefer to ride and whenever possible try to reach their destination using transport. One of our neighbours, Bair, who was a Buryat, rode a horse or bicycle when he went to the village. This was an exception in the area, where the local Evenki did not even have bicycles and preferred to travel on foot. Even if they started out by car they always managed to find reasons for conducting part of the trip on foot. In comparison to the Buryats, whose footsteps could easily be heard, the Evenki are light-footed. Bargai shared his amusement with us about how the Evenki managed to cover enormous distances without showing any signs of tiredness, and even when they had a horse they were always walking beside the animal, which was used only to carry baggage. The Buryats by contrast, tried to travel on horseback until the very last moment, and even attempted to ride in the taiga when hunting. Even their footwear was different. For the Buryats it was important to have heavy 
shoes that keep the legs warm and protect them. The Evenki sometimes made their own shoes, which were relatively light and flexible and allowed direct surface contact to the ground. They even took several pairs of shoes with them, with every pair specially designed for different surfaces and soils.

The difference in walking was obvious for Bargai, but he did not manage to learn how the Evenki walked, although he had spent a lot of time with them when he was young and they taught him how to hunt during the hard times of hunger. The Evenki taught him explicitly using explanatory words and advice, which they never did with their own children, saying that if they were born Evenki they had to know everything in advance. This difference in attitude of being much more explicit and open towards a stranger, practically secured that the Evenki way of walking was not learned by Bargai, who was not in the position of an apprentice, but just an observer, who had no clues for transforming narratives into practice. Bargai could only be amazed but failed to learn the Evenki way of walking.

Neither Bargai, nor we ourselves were able to acquire this embodied knowledge. Only after we repeatedly watched the video recording that we made quite casually with Orochon walking in front of us through the taiga during one of our trips together, did we begin to notice some features of the particular Evenki way of walking. Orochon went through an animal pathway as if he was moving in a tube with thorny bushes as walls. He was carrying a stick on which he leaned. He took this stick in his right arm, but changed hands when some branches of the bush prevented him from going further. Then he took his stick in his left hand, and used his right hand to break the branches. The sound of this cracking was rather rhythmical and synchronised with his footsteps, which we could not hear as they were rather light. There were two images that we caught after watching this tape. One is that he was marking the path with these half broken branches he left behind. We supposed that these marks will be useful in winter, when the snow will cover the path, and only such marks above the snow surface will show where the narrow path is. Orochon himself told us that it is very important to clear pathways, because this is the basis for future hunting luck. He only commented that animals also preferred to use clear pathways, and if there were any such available then there would be plenty of prey. The other point was the importance of keeping balance. Orochon was moving through the taiga in the same way as if he was floating on a boat with a stick that helped not only in pushing forwards but also in keeping his balance. When Orochon was crashing through the branches he was also balancing himself, as his leap was counterbalanced by the inertia of branches. At these moments he had four points of support as if he had not two but four legs. 


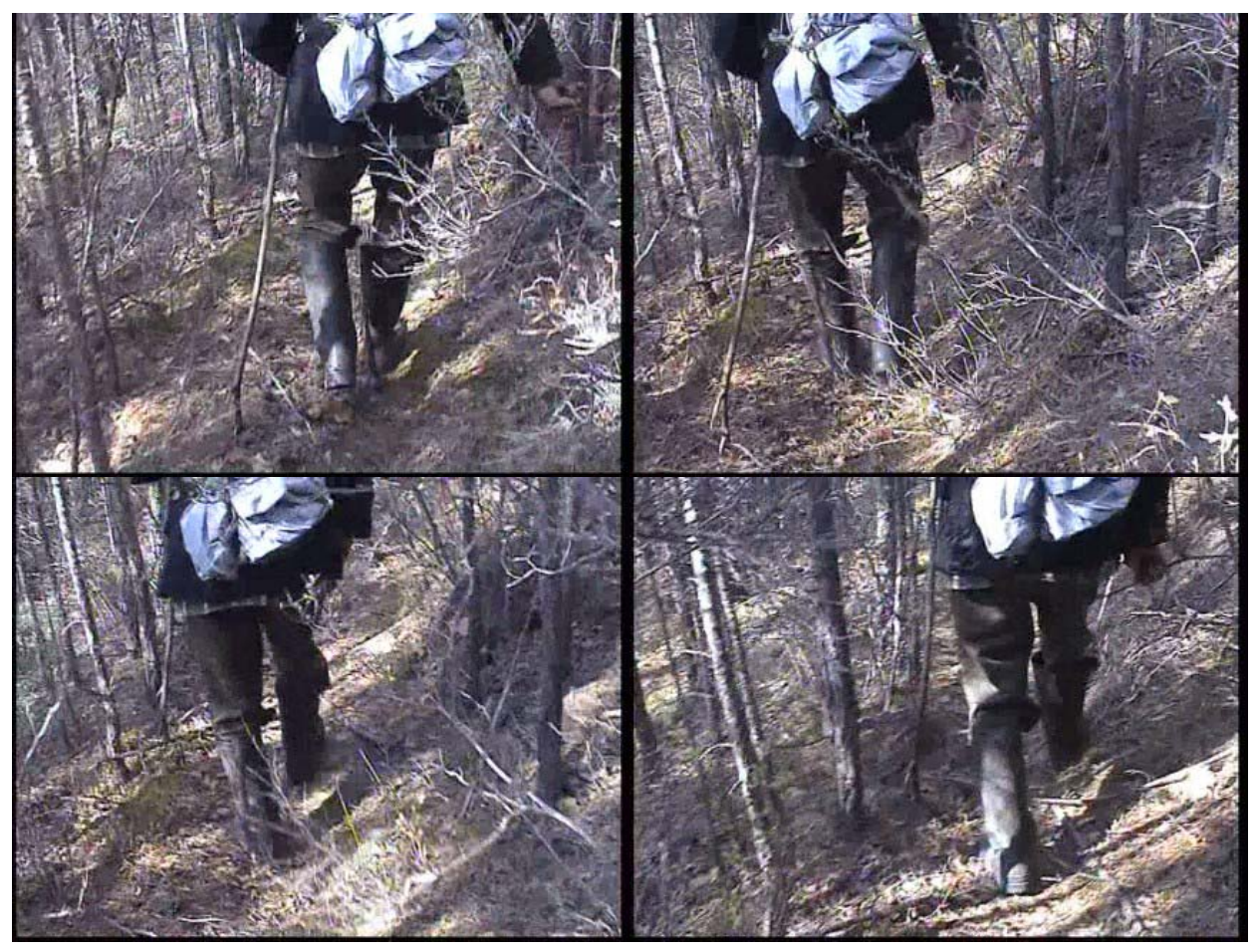

Orochon was moving smoothly, and this smoothness was achieved because he kept his balance all the time and coordinated his movements in such a way that all his muscles were involved. This kind of walking was reminiscent of the now popular Nordic walking technique using sticks, although in Orochon's case the walk was even more balanced and light. We should not forget that Orochon was already 70 years old, but his movements had not lost any of this lightness. He wore high rubber shoes through which he could feel the surface on which he walked. When we had to leave the forest and walk along the old BAM road, which was covered with stones lending it a pressed and rough surface, Orochon was obviously suffering and tried not to walk on the road, but at its side, closer to the bushes and grass. Feeling the pathway with his feet was very important, because this sense freed his eyes. Orochon never looked down to his feet, but at the surroundings, and mostly those in the distance. That helped him not to grow tired of the ever changing information of the moving objects close by, but to deal with the concrete objects at a distance, which did not change as quickly. That helped him never to lose the sense of destination and feeling of where he was. When we once asked him if there had ever been cases where an Evenki got lost in the taiga, Orochon only laughed. Even if 
drunk, Evenki could never get lost in the taiga, unless they were suffering from mental problems caused by an injury. This ability to always find your way was not even the result of sound knowledge of the territory, but the way of walking itself. Two young Evenki were hired the summer before our arrival by a party of geologists as guides and horse keepers. These two people showed the way and helped to navigate in the taiga forest that was a considerable distance away from the place where they lived. The Russian geologists were satisfied and paid them a good sum of money for their services, they hired them because they were sure that the Evenki had known the territory from their childhood. As we found out these two boys had never been there before, and entered the territory with the geologists for the first time in their lives. But their skill in finding the way and never losing their attention and involvement with the surroundings while walking worked quite well as an alternative to elaborate knowledge of the land. The Russian geologists did not even notice this 'cheating'.

To explain why the Evenki never lose their way in the forest we must examine their social organization. To be lost means at least to miss your destination and to fail to reconstruct the coordinates. Emotionally this results in a state of fear and not knowing where you are. All these experiences become even more painful if the quality of knowing and being sure are important for you to feel comfortable and even feeling yourself as human. In an egalitarian society, along with the rather schematic existence of social distinctions and roles, which are not supported by the internalized strict rules of conduct, even such routine activities as walking are not shaped by pre-existing routes and purposes. When Evenki people walk somewhere they can easily change their destination or even have no aim at all and walk just for fun or out of curiosity to see what is there. The absence of a prescribed route in practice means that the path is made by walking, that people will walk and with every next step they will change their path according to the changing circumstances. You can never know in advance where you will go. As a result of this active involvement in the process of route making losing your way is scarcely possible, as there is no place for mistakes when preconceptions are in contrast with the reality. Evenki never lose their way because they never lose their involvement in the process of walking and they do not have a prescribed purpose. Walking for the Evenki is an activity that is very concentrated on the moment, in which there is no place for other thoughts than those that are connected with the road. Walking with Evenki is a very pleasant experience, because these are the moments when they tell stories about places and the forest, when they share everything with you and when they feel themselves fully interested in the situation. 
For the Buryats the moments when they do not exactly know the geography of the place and cannot coordinate their knowledge with their practical experience are rather painful (Safonova \& Sántha 2010a). The preconception of the place is usually so strong that if there is no preconceived idea about the place, Buryat people would tend to avoid going there and would express no curiosity about it at all. Evenki people learn from their earliest years not to be frightened and to be interested in and not exclude the new possibilities of hazardous situations - for the Evenki exploring new territories is a pleasant experience. The Evenki will prefer to go and have a look just for fun, even when there is absolutely no need to go anywhere. Looking for new places is a wonderful opportunity for experiencing companionship, and as a result it is a widely accepted thing to go somewhere with the intention just to look around. In company or alone, a trip to an unknown territory is also a fine experience of manakan (which signifies 'independence' and 'solitude' in the Evenki language), because even when together with somebody else, you perceive the place in your own unique way and take your own path.

Once we participated in a ritual, in which the Evenki visited secret places in the forest. There was no obvious organization of movement from one secret place to another. Everybody was walking separately and they finally united in one place, the way hunters meet with their dogs at some moments, only to separate again without a shout or an order being given. The Evenki made their routes ever more difficult and complex. By walking in circles and making different loops they walked with the intention of looking around, thus raising their chances to come across somebody or something. The way the Evenki navigate explicitly shows their social organization, in which individuals each float freely, but are nevertheless eager for encounters and contacts with each other, uniting for a brief moment and then splitting up again to continue their individual free movement.

The emotions experienced are determined by the absence or existence of a concrete purpose for the trip. We have not only once witnessed how excited and happy the Evenki were when they were travelling without a specific purpose and also with risks (i.e. to new places) that could challenge the initial purpose. A broken wheel immediately transforms the situation during a trip, because you have to change your aims and figure out new ones, for example you need to go to your neighbours to borrow a new wheel and nobody really knows what will emerge from the new situation. Breakdowns, river crossings, drunken encounters and other occurrences, all of these incidents liberate you from the hegemony of the initial purpose, you receive the right to spontaneously change your route and combine different tasks and possible resolutions. All these conditions fill the situation with excitement and joy. In contrast to 
the predetermined purpose, for example the need to come back from the village to the camp to perform your household duties, this spoils the pleasure of the road and prevents total involvement in the travelling itself. Whenever possible the Evenki try to avoid moving under such conditions. For example, they find new reasons to stay in the village, even if they have no real place there and no money to spend. If they finally start on their way, the first coincidental encounter with someone will stop their movement and they will come back to the village accompanying the people they met. If there is no chance to escape from a trip with a predetermined aim, the Evenki look gloomy and keep silent, as if the existence of this concrete purpose prevents them from feeling free and getting pleasure from the trip.

\section{WALKING MIND}

Following the study by James Leach about the Reite people (Leach 2003), in which he described the coherence between land, kinship and person, we can also look for the same coherence in the Evenki case. The Evenki land is perceived through the possibility of companionship, the unity in social organization of the Evenki people which takes the place of kinship for the Reite. Walking great distances and through hazardous places is a practice which unites people and constitutes situated social bonds. The Evenki are nomads and thus need the rhythm of this unity and alienation, which we previously described as moments of companionship alternating with moments of manakan experiences (Safonova \& Sántha 2007). The land is the condition and scene of these meetings and separations and is thus part of the social organization itself. Without the Evenki land, which exists on the periphery of hierarchical societies, there is no possibility to conduct the Evenki nomadic way of life; this means that the Evenki land is part of the Evenki mind, which we can figuratively call a walking mind. The term mind is taken from Bateson's works and designates the pattern which connects elements and integrates the self-corrective system (Bateson 1972). The walking mind is a pattern which connects the Evenki land, Evenki companionship and Evenki people. The nomadic relational self needs space to walk through, the periodic company of others to cooperate with situationally and moments of loneliness and silence when there are no social obligations. Only the Evenki land can provide such conditions of connected isolation in which the Evenki live and which is essential to their perception of themselves.

The western distinction between mind and body is inappropriate for Evenki people, for whom motion and the ability to move from one place to another is 
the main trait of a person. Madness is the state when you cannot go or cannot fully participate in walking, and as a result you can be lost. To be lost in practical terms and to be lost mentally are identical, because there is no distinction between thinking and moving. Words that represent thoughts are about experiences of movements, news from the distant place where you have been, stories about the places you are now, which are articulated as long as you experience the place through walking together. Babushka Masha, a woman who had not been able to walk for a long time was perceived as mad and not a whole person. The youngest, Tamara, who was 3 years old and was not yet able to go together with the others and walk for long distances was also perceived as not being a full person. Dogs accompanying their human partners during their trips were persons, because they shared the experience of travelling together with the people. And for Orochon it was very important to have such a partner, because he needed the company that his wife Babushka Masha was not able to give him. The bear that lived on the neighbouring hill and which Sveta met several times during the spring we spent on camp, was also a person whom you can meet occasionally. The ability to speak and think, the ability to reciprocate or establish social relationships in their usual sense were not the criteria to ascribe to personhood. It was the ability to walk that was important and that divided the world into the animated and the non-animated. From this point of view, Evenki animism is part of their social organization in which individuals are involved if they can participate in companionship. Walking somewhere together or meeting somebody on the way are the principal and basic companionships that constitute the Evenki community. As a result, all the creatures, even the hunting prey, the bears and dogs are involved as you could meet them on the way or share the experience of walking with them.

It is also important to study children's socialization, because the first efforts to participate in others' companionship initiate the process of becoming a social creature and the first steps are the first marks of the potential to become one. Evenki people become Evenki before they start school and this explains why their culture is so resistant to assimilation. At the same time, when the Evenki are separated from their land and start to live in towns, where they have no possibility to constantly move from one place to another and experience the rhythms of loneliness and companionship, they immediately lose their identity and fully accept the main elements of the culture in which they have to integrate. The only Evenki who maintain their culture are those who succeed in having several places to stay, between which they can circulate all the time. Walking through the Evenki land and being Evenki is one and the same and it is the main prerequisite for staying with the Evenki if you are an anthropologist with the ambition of carrying out fieldwork among them. 
We once attended a ceremony, where grown ups were so drunk that they were unable and unwilling to perform the ritual. The state of manakan they experienced was sufficient to feel the sacred moment. But as the effects of the alcohol wore off, there was a need to do something together and a walk to the sacred place with the children turned out to be this common activity that somehow involved all of the participants. Kolya who was 6 years old took the initiative. Holding his grandfather's hand, he led him to the sacred place. For Orochon and Stepan it was very important to emphasize that Kolya had never before been in this place and that he showed the direction to the sacred place by intuition. They said that as he was born Evenki, he knew everything in advance and did not need instructions what to do and where to go. This appeared to be rather impressive, as Kolya was walking with some assurance carrying his little stick the same way as his grandfather held his. This walk was rather interesting, as all the participants, exhausted after several days of drinking, proceeded in the direction given by Kolya, but all the people kept to their own individual pathways. Although Orochon said that Kolya knew the place, but had never been there before, the whole party was moving more or less simultaneously, and we could not see if they were following Kolya or whether Kolya was simply coordinating his movements to the tendencies of the others. It did not matter whether Kolya knew the way or not, whether he had been there before or discovered the place by intuition. Quite possibly there was no concrete sacred place, we could never be sure. But at some point the whole party climbed a rather picturesque rock, which provided a panoramic view of the taiga. That was a sacred place, where they conducted a ritual, again led by Kolya. To our minds, it was important to state that Kolya knew the place in advance not so much to introduce magic into the situation, but more as a matter of forestalling any attempts to teach Kolya directly where to go. For the Evenki it is very important not to give express directions and orders to their children, and thus to keep their attention fixed constantly on the movements of the others, so they would learn how to see where people go, instead of asking them. These were the elements of ostensive communication, which was important for Evenki coordination within the framework of companionship.

Alcohol also forms a pretext, its availability or even its absence is a good reason for Evenki to ignore their household duties and to start a trip in search of it. Alcohol is like a trophy that must be found and drunk. The state of drunkenness is not a state in which the human mind is lost or changed, on the contrary it is a state in which the Evenki can feel themselves as full persons. This means they can look for risks, go somewhere without having a concrete purpose and look for occasional contacts and encounters. Drunkenness does 
not affect their ability to find their way in the forest, cross the river on a boat or drive a car through the night. The last moment of drunkenness is experienced as being manakan, which is associated with switching from one companionship to another. This switching is part of the Evenki mind itself and shows the rhythmic nature of their social organization, which balances loneliness with potential openness to multiple companionships and concrete involvement in the companionship.

\section{CONCLUSION}

Being nomads the Evenki are very interested in all possible means of movement and travelling. New transportation gives the possibility to move faster and carry more things. These new capacities change the world of the Evenki because as they can carry more with them, they can possess more in general. And if they have more things, it makes their life more stable, localized and less nomadic. New types of transport bring new kinds of dependencies on the outer world. The other aspect of this dependency is the fact that new transportation is either not powerful enough to cross the big distances in the taiga or it is too expensive to exploit independently. So most of the latter is controlled by strangers and the Evenki cannot use them for their own interests. Old forms of transportation such as reindeer and horses are still kept by the Evenki, although they are not used as intensively as before the integration of cars, all terrain vehicles and tractors. But until these new means of transport are not totally controlled by the Evenki, their life in the taiga is impossible without horses and reindeers.

New resources such as alcohol, petrol and money provide new causes for trips and travelling, and as such they facilitate not only the process of acculturation, but also the process of the maintenance of the Evenki culture. While the most secure mobility form for the Evenki is walking by foot, this practice is reintegrating all the aspects of the Evenki hunting ethos. What we called in this article a walking mind is a pattern that connects various aspects of Evenki culture through practice and not through narrative. Through walking together the Evenki teach their children to be autonomous persons, coordinate their actions with the Evenki dogs and conduct companionships with others. And this is how the Evenki culture is transmissible. New resources presented by the outer world construct frames for new challenges, they become trophies in new forms of hunting and as such they are assimilated into the matrix of the Evenki culture. The main finding of this research project could be summarized in a statement that moving is playing an important part in the self-correction 
(Bateson 1980) of the Evenki culture. In prospect this could lead to the comparisons with other hunter-gatherer communities. Previous approaches studied it as a part of subsistence strategy or a form of cultural transmission, but not as a device that helps to maintain a culture and counterbalance assimilation.

\section{NOTES}

1 It is a common and widely shared view that hunter-gatherers are nomadic while cultivators are settled. Recently this was questioned, because in a long term perspective hunter-gatherers tend to stay much longer on their original territories and cultivators need to move and leave their territories behind because of the ecological constraints (Brody 2001). Anyway moving is an inevitable part of the hunter-gatherer lifestyle and everyday experience.

2 The recent project on Evenki Culture is supported by the Hungarian Scientific Research Fund. The fieldwork this paper is based on was supported by the Siberian Studies Centre at The Max Planck Institute for Social Anthropology and the Ministry of Culture in Hungary (2006). Our ideas on walking were developed at the Institute for Advanced Studies of Klagenfurt University during our two month stay in Graz, Austria. Our participation in the conference on Northern Routes in Tartu in May 2010 was possible with the financial assistance of the Hungarian Committee of Fenno-Ugrian Peoples (especially thanks to Eva Rubovszky), the Hungarian Cultural Centre in Tallinn and the Department of Ethnology at the University of Tartu. And finally we thank for their helpful reviews Art Leete, Aimar Ventsel and Peter Schweitzer.

${ }^{3}$ The first version of the following part of the article was published as a research report (Safonova \& Sántha 2010b).

\section{REFERENCES}

Bateson, Gregory 1972. Steps to an Ecology of Mind: Collected Essays in Anthropology, Psychiatry, Evolution, and Epistemology. San Francisco: Chandler.

Bateson, Gregory 1980. Mind and Nature - A Necessary Unity. Bantam Books.

Brody, Hugh 2001. The other side of Eden. Hunter-Gatherers, Farmers and the Shaping of the World. London: Faber and Faber.

Ingold, Tim \& Vergunst, Jo 2008 (eds.) Ways of Walking. Ethnography and Practice on Foot. Aldershot: Ashgate.

Kelly, Robert L. 1995. The Foraging Spectrum: Diversity in Hunter-Gatherer Lifeways. Washington: Smithsonian Institute Press.

Kwon, Heonik 1998. The Saddle and the Sledge. Hunting as Comparative Narrative in Siberia and Beyond. The Journal of the Royal Anthropological Institute (MAN). Vol. 4, No 1, pp. 115-127. 
Lave, Jean \& Wenger, Etienne 1991. Situated Learning: Legitimate Peripheral Participation (Learning in Doing: Social, Cognitive and Computational Perspectives). Cambridge: Cambridge University Press.

Leach, James 2003. Creative Land: Place and Procreation on the Rai Coast of Papua New Guinea. Oxford, New York: Berghahn.

Legat, Allice 2008. Walking Stories; Leaving Footprints. In: T. Ingold \& J. Vergunst (eds.) Ways of Walking. Ethnography and Practice on Foot. Aldershot: Ashgate, pp. 35-49.

Safonova, Tatiana \& Sántha, István 2007. Companionship among Evenki of Eastern Buryatia: The Study of Flexible and Stable Elements of Culture. Working Papers of Max Planck Institute for Social Anthropology, No 99. Halle/Saale: Max Planck Institute for Social Anthropology.

Safonova, Tatiana \& Sántha, István 2010a. Different Risks, Different Biographies: The Roles of Reversibility for Buryats and Circularity for Evenki people. Forum Qualitative Sozialforschung / Forum Qualitative Social Research. Special issue: Biography, Risk and Uncertainty. Vol. 11, No.1. http://nbn-resolving.de/ urn:nbn:de:0114-fqs100111, last accessed 2 Dec 2011.

Safonova, Tatiana \& Sántha, István 2010b. Walking Mind: The Pattern that Connects Evenki Land, Companionship and Person. In: A. Bammé \& G. Getzinger \& B. Wieser (eds.) Yearbook 2009 of the Institute for Advanced Studies on Science, Technology and Society. München, Wien: Profil, pp. 311-323.

Ssorin-Chaikov, Nikolay 2003. The Social Life of the State in Subarctic Siberia. Stanford: Stanford University Press.

Tuck-Po, Lye 2008. Before a Step Too Far: Walking with Batek Hunter-Gatherers in the Forest of Pahang, Malaysia. In: T. Ingold \& J. Vergunst (eds.) Ways of Walking. Ethnography and Practice on Foot. Aldershot: Ashgate, pp. 21-34.

Widlok, Thomas 2008. The Dilemmas of Walking: A Comparative View. In: T. Ingold \& J. Vergunst (eds.) Ways of Walking. Ethnography and Practice on Foot. Aldershot: Ashgate, pp. 52-66. 